\title{
SISTEMA DE MONITORAMENTO VEICULAR - SETORES SUCROALCOOLEIROS: A TECNOLOGIA DA INFORMAÇÃO A SERVIÇO DA GESTÃO EMPRESARIAL
}

\author{
André Luis Novaes, Lechan Colares Santos \\ Universidade do Oeste Paulista - UNOESTE, Presidente Prudente, SP.
}

\section{RESUMO}

O presente artigo visa apresentar a influência da Tecnologia de Informação - TI no gerenciamento das empresas, mais especificamente as do setor sucroalcooleiro, tornando-as ágeis e eficazes, demonstrando suas consequências na melhoria dos processos de gestão empresarial com informações disponibilizadas em tempo real pelo sistema, aprimorando seus processos de venda e distribuição, tornando-se mais eficientes, melhorando a comunicação e agilizando os processos que antes eram imprecisos, de modo que se possa evitar investimentos inadequados para a organização. Utilizou-se referências bibliográficas na área de $\mathrm{TI}$, tendo como foco o sistema de monitoramento veicular, trabalhando junto com o sistema GPS (Global Positioning System) e o computador de bordo, que atende grande parte dos requisitos de automação necessários para o controle do setor envolvido, coletando todas as informações necessárias o bordo junto de um software cria pacotes de dados que são enviados ao servidor via GPRS (Serviços Gerais de Pacote por Rádio) depois são processados para que seja visualizado de uma maneira fácil e dinâmica no SGPA (Sistema Gerenciado Processo Automatizado), e gerenciamento de empresas para obtenção de abrangência do assunto. Concluindo-se que a adoção da TI possibilita a praticidade e confiabilidade de relatórios on-line ou relatórios gerenciais sabendo de forma precisa o percentual de horas trabalhadas, manutenção mecânica de seus equipamentos e vários outros fatores, gerando uma economia satisfatória com muita agilidade e controle, proporcionando uma maior quantidade e qualidades dos seus produtos.

Palavras-chave: Monitoramento veicular, Novas tecnologias, Gestão empresarial GPS, SGPA.

VEHICLE MONITORING SYSTEM - SUCROALCOOLERY SECTORS: AT THE SERVICE OF BUSINESS MANAGEMENT

INFORMATION TECHNOLOGY

\begin{abstract}
This article aims to present the importance of Information Technology - IT in the management of companies, such as those in the sugar and alcohol industry, making them agile and efficient, demonstrating its consequences in the improvement of business management processes with information made available in real time by the system, Improving their sales and distribution processes, making them more efficient, improving communication and streamlining processes that were previously inaccurate, so that inappropriate investments can be avoided for the organization. Bibliographical references were used in the IT area, focusing on the vehicle monitoring system, working together with the Global Positioning System (GPS) and the On-board Computer, which fulfills a large part of the automation requirements necessary to control the sector Involved, collecting all the necessary information the board next to a software creates data packets that are sent to the server via GPRS (General Radio Package Services) after they are processed so that it is viewed in an easy and dynamic way in the SGPA (Managed System Automated Process), and business management to gain comprehensiveness of the subject. It is concluded that the adoption of IT enables the practicality and reliability of online reports or
\end{abstract}


managerial reports knowing precisely the percentage of hours worked, mechanical maintenance of its equipment and several other factors, generating a satisfactory economy with great agility and control, Providing a greater quantity and qualities of its products.

Keywords: Vehicle monitoring, New technologies, Business management, GPS, SGPA.

\section{Introdução}

Neste artigo, relata-se alguns pensares sobre a importância da tecnologia da informação que hoje, está disponível às empresas, como as do setor sucroalcooleiro. Procurou-se entender as significativas ações da tecnologia de informação nestas empresas, e para atingir estes objetivos, foi feita uma pesquisa bibliográfica e um pequeno estudo de caso acerca da importância da aplicação de novas tecnologias em determinadas áreas, como o sistema de monitoramento veicular em usinas sucroalcooleiras, observando-se o impacto e possível otimização do controle geral de equipamentos, apontamentos e demais benefícios que possam acarretar.

Em linhas gerais, o objetivo da pesquisa é oferecer aos técnicos de T.I. e demais profissionais ligados à área, a ampliação de seus conhecimentos referentes às novas tecnologias de sistema de monitoramento veicular. Salientando a importância da presença destas novas tecnologias, que beneficiam e amparam com eficácia as necessidades de monitoramento e registros em diversas áreas de trabalho.

Num segundo momento, a pesquisa preocupou-se em destacar as novas tecnologias de sistema de monitoramento veicular com ênfase no Computador de Bordo, sendo este, dependente do sistema GPS; O computador de bordo coleta informações do equipamento operador e sua localização pelo GPS, processando todos esses dados e condições junto de um software criando pacotes de dados e transmitindo via GPRS ao servidor, onde são transformados em informações do SGPA - Sistema Gerenciado Processo Automatizado - para serem visualizadas.

Por fim, o terceiro capítulo destinou-se a apontar os benefícios que a Automação pelo Computador de Bordo gera á usinas sucroalcooleiras. Efetuando medições e introduzindo correções, a automação diminui os custos e aumenta a velocidade da produção, aumentando assim a produtividade.

É importante ressaltar que, as ferramentas de trabalho de alta tecnologia aqui mencionadas, auxiliam o gerenciamento e a economia de uma empresa como um todo, sendo indispensável para o sucesso de uma grande empresa, justificando assim, a presença de um parecer ou uma interpretação que a pesquisa vem oferecer.

\section{Metodologia}

A presente pesquisa trata-se de levantamento teórico, acompanhada de aplicabilidade prática $\mathrm{O}$ método adotado para a pesquisa deste artigo foi a qualitativa, pois se faz uma relação entre o tema e o ambiente organizacional. $O$ tipo de pesquisa utilizado foi a exploratória, pois envolveu levantamentos bibliográficos e análise de exemplos para melhor compreensão. Dando continuidade ao processo utilizado nesta pesquisa, dentre os procedimentos técnicos, foi utilizada a pesquisa bibliográfica, pois fundamentaliza o artigo em caráter científico. Este artigo se baseia em um estudo de caso sendo analisado o computador de bordo com levantamento estatísticos do mesmo de setor sucroalcooleiro na região de vista alegre do alto-sp. Utilizou-se, como elementos de análise, referências bibliográficas de diversos autores, que referenciam a TI como instrumento no gerenciamento às empresas.

Diante de um controle maior de seus equipamentos e apontamentos e de seus funcionários as grandes empresas do setor sucroalcooleiro buscam novas tecnologias de automação para saciar suas necessidades. 
Visando suprir suas necessidades neste setor empresas especializadas desenvolvem sistemas para monitoramento e rastreamento de veículos com computadores de bordo com eficácia de $99 \%$ em suas operações automáticas. Oferecendo a este setor uma segurança maior no controle de suas frotas e funcionários nas frentes de colheitas de cana de açúcar e todas as demais áreas envolvidas em grandes usinas do setor sucroalcooleiro.

O sistema de monitoramento veicular tem se aprimorado rapidamente, principalmente em virtude das novas necessidades do mercado e pelo avanço tecnológico. Com isso, percebe-se que muitas empresas têm se beneficiado das informações disponibilizadas em tempo real pelo sistema automatizado de monitoramento veicular, aprimorando seus processos e economizando equipamentos e combustível tornando-se mais eficientes, melhorando a comunicação e agilizando os processos que antes eram imprecisos.

\section{Resultados}

A pesquisa procurou demonstrar os benefícios da implementação prática desses novos recursos tecnológicos ao sistema de monitoramento veicular em usinas sucroalcooleiras, oferecendo um gerenciamento maior de logística, maior controle de suas frotas e funcionários, economia significativa em seus equipamentos nas frentes de colheitas de cana de açúcar e demais áreas envolvidas. Conclui-se que, para as organizações se manterem competitivas neste mercado que oscila a cada dia, elas devem estar acompanhando as ocorrentes mudanças em torno dela. Existem vários aplicativos disponíveis no mercado para efetuar rastreamento e monitoramento de veículos. Dentre eles pode-se citar o SGPA (Sistema Gerenciado Processo Automatizado) usado no maquinário de usinas do setor sucroalcooleiro. O SGPA - "Sistema Gerenciado Processo Automatizado" é um sistema completo de gerenciamento das atividades e de comunicação direta com todos os equipamentos que possuem um Computador de Bordo. (SOLINFTEC, 2012, p.28).

O sistema possibilita efetuar vários tipos de cadastros, bem como monitorar todos os processos em tempo real dos equipamentos, além de poder fazer consultas de todas as ocorrências passadas, das entradas de informações, através de relatórios do sistema. Tratando-se do monitoramento, existem várias funções, como por exemplo, estatísticas das informações (técnicas e operacionais) dos equipamentos, alarmes informativos de problemas ou avisos definidos por regra; podem-se gerar rastros dos trajetos feitos pelos equipamentos, e até enviar mensagens e comandos online para o Computador de Bordo, a fim de que se possa expedir uma informação ao condutor e ter melhores resultados ao gerir o sistema de trabalho da empresa. 0 SGPA tem a característica de web, ou seja, pode ser acessado de qualquer terminal que possua uma comunicação com a internet, e por qualquer navegador de internet. Com o computador de bordo é possível realizar um importante controle do gerenciamento de logísticas das operações realizadas em uma usina sucroalcooleira, de uma base operacional, "no caso a balança da usina", onde se tem o controle de todas as operações. Com o aceso ao sistema SGPA, visualiza-se em tempo real todos os maquinários no qual estão instalados os computadores de bordo.

Se as organizações não souberem utilizá-lo a seu favor, essas estarão perdendo seus espaços. Os gestores da era digital têm uma função importantíssima, a de identificar a tecnologia adequada para que esta atenda as reais necessidades de suas empresas, sabendo que irá mudar toda a cultura organizacional, incluindo a qualificação profissional de seus funcionários e colaboradores.

O processo de uso estratégico da informação que pode vir a gerar o diferencial competitivo, da maneira como estas informações serão utilizadas nos processos e serviços das empresas e no ambiente de negócios. Portanto, torna-se indispensável sua utilização, desde que 
seja feito um planejamento estratégico, visando todas estas mudanças ocorrentes na implantação das Tecnologias das Informações.

\section{Considerações finais}

Pretende-se neste artigo apontar como avanços tecnológicos e equipamentos de alta tecnologia para a automação dos processos agrícolas ampliaram e modernizaram a produtividade em grandes empresas como uma usina sucroalcooleira. Automação é um sistema automático de controle pelo qual os mecanismos verificam seu próprio funcionamento, efetuando medições e introduzindo correções. A automação diminui os custos e aumenta a velocidade da produção. LACOMBE (2004, p.36).

Na sociedade contemporânea não é mais possível negar que as novas tecnologias estão presentes nas experiências diárias dos indivíduos e saber beneficiar-se delas para aperfeiçoar o trabalho torna-se imprescindível, atualmente, a automação está presente em diferentes níveis de atividades do homem, desde as residências, no trânsito, através de sistemas de controle de tráfego e sinalização, nos edifícios comerciais, processos de compra, venda e transporte de bens, processos industriais primários e secundários.

Tecnologia da informação vem a ser qualquer sistema usado para fornecer informações (incluindo seu processamento), que podem auxiliar os administradores na tomada de decisão dentro das empresas, qualquer que seja sua utilização (BEAL, 2001).

A principal motivação para se adotar a tecnologia nas empresas é a necessidade de uma melhor utilização dos recursos financeiros, investidos em máquinas e manutenção dos sistemas computacionais das empresas. A Gestão da Informação surge para sanar ineficiências, aliando conceitos da Gestão Estratégica à Tecnologia de Informação, nas empresas, com o objetivo de sistematizar e organizar o conhecimento, os dados e as informações. A Gestão da Informação, de acordo com a descrição de Braga (2007), tem a função de política da empresa, o que possibilita a interação entre as várias "partes" que a constituem, e tem como objetivo apoiar sua política global. Em suma, trata-se da: [...] gestão eficaz de todos os recursos de informação relevantes para a organização, tanto a de recursos gerados internamente, como os produzidos externamente e fazendo apelo, sempre que necessário, à tecnologia da informação (BRAGA, 2007:03).

O futuro do sistema de navegação por satélite é extremamente promissor e de crescimento exponencial junto com o desenvolvimento tecnológico. Este pode ser definido como "um poderoso conjunto de ferramentas para captura, armazenamento, recuperação, transformação e representação espacial de dados do mundo real para análise de acordo com finalidades especificas" (BURROUGH; MCDONNELL, 2004, p.11, tradução do autor). Esta necessidade imprescindível de obtenção de coordenadas geográficas precisas em tempo real já é uma realidade para diversos segmentos da atividade humana.

Este estudo teve como referência uma das alternativas presente no mercado brasileiro na automatização do monitoramento veicular. O sistema analisado é comercializado pela empresa Solinftec - Automação Industrial, que utiliza o software SGPA - "Sistema Gerenciado Processo Automatizado". A análise de funcionalidades do software foi realizada durante a utilização do mesmo na Empresa Nardini Agroindustrial Ltda, localizada no município de Vista Alegre do Alto, Estado de São Paulo.

A empresa teve grande avanço em sua produção após a utilização deste sistema. Tornando-se referência no setor sucroalcooleiro pelo crescimento sustentável e qualidade de seus produtos. Atualmente, a empresa possui uma capacidade de moagem de aproximada de 3,7 milhões de toneladas de cana-de-açúcar por safra. 
Para ter um controle maior de seus funcionários e equipamentos as usinas utilizam procedimentos para obter os apontamentos dos funcionários, em relação às operações e tempos de utilização efetiva dos equipamentos, além de muitos outros benefícios que são utilizados para melhorar os procedimentos e regularizar alguns processos. Estes apontamentos são feitos manualmente por meio de fichas de apontamento ou de outros dispositivos, isto gera nas informações pouca confiabilidade, pois dependerão dos apontamentos manuais dos operadores.

A Automação de Monitoramento traz benefícios para os apontamentos, substituindo a ficha de apontamentos e outros dispositivos, pois através do computador de bordo instalado no equipamento ele detecta os sinais e estados automaticamente do equipamento e envia os dados de apontamento e monitoramento para um servidor e pode ser acessado de um computador ou smartphone através do software do monitoramento SGPA. Isto aumenta a confiabilidade nos dados e traz o real tempo efetivo dos equipamentos nas operações produtivas além de ter a possibilidade de monitorar a frota em suas diversas frentes de trabalho e gerar relatórios gerenciais e relatórios on-line.

Diante deste quadro, tornam-se necessário analisar criteriosamente, as diversas alternativas existentes no mercado de sistemas informáticos para a automatização de ativos móveis, processos de logística e sistemas de rastreamento e monitoramento por satélite, com o objetivo de encontrar opções viáveis, a fim de que se possa expedir informação mais precisas e ter melhores resultados ao gerir o sistema de trabalho da empresa.

A presente pesquisa busca oferecer um respaldo afim de que nos posicionemos frente à própria formação profissional mediante as novas tendências e exigências que se formam, utilizando estas ferramentas para aperfeiçoar as atividades em que estão envolvidos, elevando a precisão e produtividade com singular interpretação, facilitando o desenvolvimento e crescimento econômico de forma significativa.

\section{REFERÊNCIAS}

BEAL, Adriana. O sistema de informação como estratégia empresarial. São Paulo: Atlas, 2001.

BERALDI, Lairce; ESCRIVÃO FILHO, Edmundo. Impacto da tecnologia de informação na gestão de pequenas empresas. Revista Ciência da Informação, Brasília, v. 29, n. 1, jan./abr. 2000.

BRAGA, Ascenção. A gestão da informação. Disponível em http://www.arquivar.com.br/espaco profissional/sala leitura/artigos/Gestao da Informacao.pdf Acesso em: 30 abr. 2017.

BURROUGH, Peter A.; MCDONNELL, Rachel A. Principles of Geographic Information Systems. 6. ed. New York: Oxford University Press, 2005.

CABRAL R. B.; SPERB R. M.; ZANATO R. Tecnologia Opensource para Rastreamento Online de Veículos Monitorados via Satélite. In: Congresso Brasileiro de Computação - CBComp - Sistemas de Informação, 2, 2002, Campinas, 2002.

DORF, Richard C; BISHOP, Robert H. Sistemas de controle modernos - 8.ed / 2001 8.ed. Rio de Janeiro, RJ: Livros Técnicos e Científicos, 2001.

LACOMBE. F.J.M.Dicionario de Administração.[SI]: Saraiva,2004. 
NARDINI Agroindustrial Ltda. Institucional. Desenvolvido por Inventandus | Julio Guimarães Disponível em: http://www.nardini.ind.br/pt/institucional Acesso em 30 de abr. 2017

SOLINFTEC - Automação Industrial. Introdução aos processos da Usina E Monitoramento veicular. Araçatuba SP. 2012.

Manual do Sistema SGPA. Araçatuba SP. 2012.

Software de Monitoramento e Controle SGPA Design by DEP propaganda. Disponível em: http://www.solinftec.com/?page id=280 acesso em 30 abr. 2017.

Soluções de monitoramento. Design by DEP propaganda. Disponível em: http://www.solinftec.com/?page id=280 acesso em 30 abr. 2017. 